\title{
Impact of quercetin-induced changes in drug-metabolizing enzyme and transporter expression on the pharmacokinetics of cyclosporine in rats
}

\author{
YANI LIU* ${ }^{*}$ XIAOMEI LUO* ${ }^{*}$ CHUNXIAO YANG, TINGYU YANG, JIALI ZHOU and SHAOJUN SHI \\ Department of Pharmacy, Union Hospital, Tongji Medical College, \\ Huazhong University of Science and Technology, Wuhan, Hubei 430022, P.R. China
}

Received August 28, 2015; Accepted May 17, 2016

DOI: $10.3892 / \mathrm{mmr} .2016 .5616$

\begin{abstract}
The aim of the present study was to evaluate whether quercetin (Que) modulates the mRNA and protein expression levels of drug-metabolizing enzymes (DMEs) and drug transporters (DTs) in the small intestine and liver, and thus modifies the pharmacokinetic profile of cyclosporine (CsA) in rats. This two-part study evaluated the pharmacokinetic profiles of CsA in the presence or absence of Que (experiment I) and the involvement of DMEs and DTs (experiment II). In experiment I, 24 rats received single-dose $\mathrm{CsA}(10 \mathrm{mg} / \mathrm{kg})$ on day 1 , single-dose Que (25, 50 and $100 \mathrm{mg} / \mathrm{kg} / \mathrm{day}$; eight rats in each group) on days 3-8, and concomitant CsA/Que on day 9. In experiment II, the mRNA and protein expression levels of cytochrome $\mathrm{P}$ (CYP)3A1, CYP3A2, UDP glucuronosyltransferase family 1 member A complex locus, organic anion-transporting polypeptide (OATP)2B1, OATP1B2, P-glycoprotein, breast cancer resistance protein, and multidrug resistance-associated protein 2 in the small intestine and liver of rats were analyzed following oral administration of Que at 25, 50 and $100 \mathrm{mg} / \mathrm{kg}$ in the presence or absence of CsA (10 mg/kg) for seven consecutive days. Co-administration of Que $(25,50$ and $100 \mathrm{mg} / \mathrm{kg})$ decreased the maximum serum concentration of CsA by 46,50 and $47 \%$ in a dose-independent manner. In addition, the area under the curve to the last measurable concentration and area under the curve to infinite time were decreased, by 21 and 16\%, 30 and $33 \%$, and 33 and $34 \%(\mathrm{P}<0.01)$, respectively. However, the mRNA and protein expression levels of the above-mentioned DMEs
\end{abstract}

Correspondence to: Dr Shaojun Shi, Department of Pharmacy, Union Hospital, Tongji Medical College, Huazhong University of Science and Technology, 1277 Jiefang Avenue, Wuhan, Hubei 430022, P.R. China

E-mail: sjshicn@163.com

*Contributed equally

Key words: quercetin, cyclosporine, pharmacokinetics, drug-metabolizing enzymes, drug transporters, mRNA, protein, interplay and DTs were inhibited by Que in a dose-dependent manner $(\mathrm{P}<0.01)$ to a similar extent in the small intestine and liver. It was demonstrated that Que was able to reduce the bioavailability of CsA following multiple concomitant doses in rats. Overlapping modulation of intestinal and hepatic DMEs and DTs, as well as the DME-DT interplay are potential explanations for these observations.

\section{Introduction}

Flavonoids are important phytochemicals, prevalent in the human diet, which are claimed to exert a variety of biological effects (1). Herbal preparations containing high doses of flavonoids have become widespread as interest in healthy living and alternative medicine increases. Therefore, potential herb-drug interactions (HDIs) may be a major concern in the co-administration of flavonoids and other medicines $(2,3)$.

Quercetin (3,3',4',5,7-pentahydroxyflavone; Que), the predominant flavonoid, is ubiquitously present in edible plants, herbs, beverages and dietary supplements, including onions, grapes, berries, apples, red wine, tea, St. John's wort and ginkgo (3). Due to its beneficial effects on health, it has also been marketed as a dietary supplement (3), with a recommended daily dose of 200-1200 mg (4). It exhibits antioxidant, anti-inflammatory, anticancer, neuroprotective, anti-anaphylaxis and anti-aging effects (5-7). In addition, Que is well-known to protect tissue against damage induced by chemicals. For example, Que protects against cyclosporine (CsA)-induced nephrotoxicity and hepatotoxicity $(8,9)$, acetic acid- and trinitrobenzene sulphonic acid-induced inflammatory bowel disease-like symptoms $(10,11)$, atrazine-induced cytotoxicity in cultured Sertoli-germ cells and Leydig cells $(12,13)$, ethanol-induced dyslipidemia and mitochondrial oxidative damage (14), and high glucose-induced Schwann cell damage (15).

It has been reported that Que modulates the phase I and phase II drug-metabolizing enzymes (DMEs), including cytochrome P (CYP) 1A1, CYP1A2, CYP1B1, CYP2A6, CYP2C9, CYP2D6, CYP3A4, UDP glucuronosyltransferases (UGTs) and sulfotransferases (SULTs) (16-20), and drug transporters (DTs), including P-glycoprotein (P-gp), multidrug resistance-associated protein 1 (MRP1), breast cancer resistance 
protein (BCRP), organic anion transporter (OAT) and organic cation transporter (16,21-23). However, the effect of Que on DMEs and DTs in vitro and in vivo $(16,24-26)$ remains to be elucidated.

As a calcineurin $(\mathrm{CN})$ inhibitor, $\mathrm{CsA}$ is widely used to prevent rejection of transplanted organs (27). It is a substrate for CYP3A and P-gp (27), UGT1A and 2B (28), and MRP2 (29). However, it is also a potent inhibitor of CYP3A4, P-gp, OATP1B and 2B, MRP2, and BCRP $(30,31)$. Consequently, foods or dietary supplements that influence DMEs, DTs and/or their interplay may alter the pharmacokinetics of CsA, resulting in increased toxicity and/or diminished efficacy. Previous studies have reported that Que interacts with $\mathrm{CsA}$ resulting in a reduction or increase in the serum concentration of CsA (31-37). These conflicting results may be due to differences in the subjects used, the method of administration and the dose. Furthermore, the underlying mechanisms by which the effects of Que are mediated are poorly understood.

Increased knowledge of the interactions between DMEs and DTs in drug absorption and disposition, as well as complex HDIs, facilitates prediction of the pharmacokinetic properties of drugs and potential HDIs $(38,39)$. There may be serious risks, particularly for drugs such as CsA with a narrow therapeutic index, if other drugs or food constituents that interfere with DMEs and DTs are deliberately or unintentionally co-administered (37).

As a novel CN inhibitor, Que demonstrates noncompetitive inhibition of CN (40), suggesting that it may have immunosuppressant properties and may potentially enhance the effect of CsA. As Que is widely distributed in foods and is available as a dietary supplement, Que and CsA may frequently be administered simultaneously. It is therefore crucial to understand the effect of Que on DMEs and DTs, and their interactions. Thus far, to the best of our knowledge, there have been no studies investigating the simultaneous modulation of DME and DT expression levels by Que in the small intestine and liver.

The aim of the present study was to evaluate whether multiple-dose oral administration of Que influenced the pharmacokinetics of CsA in rats. Furthermore, to investigate the underlying mechanisms, reverse transcription-quantitative polymerase chain reaction (RT-qPCR) and western blotting were performed to measure the mRNA and protein expression levels of DMEs and DTs in the small intestine and liver of rats, following Que consumption in the presence or absence of CsA for seven consecutive days.

\section{Materials and methods}

Materials. Que, CsA and Cyclosporine D were purchased from Sigma-Aldrich (St. Louis, MO, USA). The CsA formulation was Sandimmune ${ }^{\circledR}$ injection $(50 \mathrm{mg} / \mathrm{ml}$; Novartis International AG, Basel, Switzerland) containing Cremophor ${ }^{\circledR}$ EL (polyethoxylated castor oil), and each $\mathrm{ml}$ of infusion concentrate was diluted in de-ionized water prior to use. TRIzol ${ }^{\circledR}$ reagent was purchased from Invitrogen; Thermo Fisher Scientific, Inc. (Waltham, MA, USA). Cremophor ${ }^{\circledR}$ EL was obtained from BASF SE (Ludwigshafen, Germany). The first-strand complementary (c) DNA synthesis kit and THUNDERBIRD SYBR qPCR Mix were purchased from Toyobo Co., Ltd. (Osaka,
Japan). Milli-Q plus water (EMD Millipore, Billerica, MA, USA) was used for all preparations.

Animals. Male Sprague-Dawley (SD) rats weighing 180-220 g were purchased from the Laboratory Animal Research Center of Tongji Medical College of Huazhong University of Science and Technology (Wuhan, China), and were given free access to a commercial rat chow diet (low Que) and tap water. The animals were housed two per cage, and maintained at $22 \pm 2^{\circ} \mathrm{C}$ and $50-60 \%$ relative humidity, under a 12-h light/dark cycle. The experiments were initiated following acclimation to these conditions for at least one week. All experiments were performed with the approval of the Animal Research Ethics Committee of Union Hospital of Huazhong University of Science and Technology (permit no. 2015-015; Wuhan, China).

Experiment I. A total of 24 rats were randomly divided into three groups, and received either solely CsA or an identical dose of CsA together with low-, moderate- or high-dose Que in a before-and-after design. The rats were fasted for $12-\mathrm{h}$ prior to dosing, and food was also withheld for $3 \mathrm{~h}$ subsequent to dosing. Water was supplied ad libitum. The CsA solution was prepared by diluting Sandimmune ${ }^{\circledR}$ injection with de-ionized water to a concentration of $2 \mathrm{mg} / \mathrm{ml}$. Que was dissolved in vehicle (Cremophor ${ }^{\circledR}$ EL/de-ionized water). Drugs were administered by oral gavage using a 16-gauge gavage needle (Kent Scientific Corporation, Torrington, CT, USA). On day 1, 24 rats assigned to the low-dose, moderate-dose and high-dose Que treatment groups received a single oral dose of $10 \mathrm{mg} / \mathrm{kg} \mathrm{CsA}$ alone. From days 3 to 8 , rats received 25, 50 or $100 \mathrm{mg} / \mathrm{kg} /$ day of Que for six consecutive days. Following the final dose, rats were fasted overnight with free access to water. The following morning, Que was again administered, followed $0.5 \mathrm{~h}$ later by CsA (10 mg/kg dose). The dosages were selected based on clinical doses administered to humans. Cremophor ${ }^{\circledR}$ EL was added to the vehicle to ensure Que dissolution and accurate dosing. On experimental days 1 and 9, blood samples $(0.2 \mathrm{ml})$ were collected via the tail vein prior to, and at $0.5,1$, $3,5,8,12,24,36$ and $48 \mathrm{~h}$ following, CsA administration and deposited into heparinized tubes (BD Biosciences, Franklin Lakes, NJ, USA). Blood samples were stored at $-80^{\circ} \mathrm{C}$ until analysis.

Experiment II. Rats were randomly divided into eight groups with three rats in each group. Rats in the Que-treated groups were gavaged once daily with Que at 25,50 or $100 \mathrm{mg} / \mathrm{kg}$ without (Que-WOC) or with (Que-WC) CsA (10 mg/kg) for 7 consecutive days. Rats in the CsA-treated group were gavaged once daily with CsA $(10 \mathrm{mg} / \mathrm{kg})$ for 7 consecutive days. Rats in the CsA-treated group were only gavaged with CsA (10 mg/kg); however, the Que-WC group were treated with Que and CsA by two separate gavages within 1 min. Rats in the control group were similarly gavaged with the equivalent volume $(5 \mathrm{ml} / \mathrm{kg})$ of vehicle $\left(\right.$ Cremophor ${ }^{\circledR} \mathrm{EL} / \mathrm{de}$-ionized water). Animals were allowed free access to food and water throughout the experiment; however, they were fasted overnight prior to sacrifice to reduce the intestinal content. On day $7,0.5 \mathrm{~h}$ following the final dose, rats were sacrificed by cervical dislocation. Tissues, including the small intestine 
Table I. Summary of the gene-specific polymerase chain reaction primer sequences, product size and annealing temperature.

\begin{tabular}{|c|c|c|c|c|c|}
\hline Description & Genebank & Sense primer, $5^{\prime}-3^{\prime}$ & Antisense primer, 5'-3' & $\begin{array}{l}\text { Product } \\
\text { size, bp }\end{array}$ & $\begin{array}{c}\mathrm{Tm}, \\
{ }^{\circ} \mathrm{C}\end{array}$ \\
\hline$\beta$-actin & NM_031144 & CGTTGACATCCGTAAAGACCTC & TAGGAGCCAGGGCAGTAATCT & 110 & 58 \\
\hline Cyp3a1 & NM_013105.2 & ACTGCATTGGCATGAGGTTTG & ATCCCGTGGCACAACCTTT & 170 & 58 \\
\hline Cyp3a2 & NM_153312.2 & ATTCTAAGCATAAGCACCGAGTG & TGTGCTGCTGGTGGTTTCAT & 158 & 58 \\
\hline Ugt1a1 & NM_012683.2 & АСТАTTCTTGTCAAATGGCTACCC & GTTTTCCAAATCATCGGCAGT & 231 & 58 \\
\hline Slco2b1 & NM_080786.1 & TCGCTGTTGTGTCTGCTACTCAG & AACAGGGTTAAAGTCATCTGATTGG & 162 & 58 \\
\hline Slco1b2 & NM_031650.3 & TTCGTGGTGATAAGAAGCCG & CAATTCAGGTTGGACGCTCTT & 162 & 58 \\
\hline Mdr1 & NM_012623.2 & TCCTATGCTGCTTGTTTCCG & ATCCTGATGATGTGGGATGCT & 179 & 58 \\
\hline Bcrp1 & NM_181381.2 & ATTGGTGCCCTTTACTTTGGTC & ACACTTGGCAAGAACCTCATAGG & 236 & 58 \\
\hline Mrp2 & NM_012833.2 & TGTGGCAGTTGAGCGAATAAGT & AAGAGGCAGTTTGTGAGGGATG & 246 & 58 \\
\hline
\end{tabular}

Tm, annealing temperature; Cyp, cytochrome P; Ugt1a1, UDP glucuronosyltransferase family 1 member A complex locus; Slco, solute carrier organic anion transporter family member; Mdr1, multi-drug resistance 1; Bcrp, breast cancer resistance protein; Mrp2, multidrug resistance-associated protein 2 .

and liver, were isolated, rinsed with saline, blotted dry, snap-frozen in liquid nitrogen and stored at $-80^{\circ} \mathrm{C}$ until use.

Detection of the cyclosporine blood concentration in rats by liquid chromatography-tandem mass spectrometry (LC-MS/MS). Blood concentrations of CsA were measured using validated LC-MS/MS using an internal standard of Cyclosporine D. The standards in the rat samples were analyzed on an API-4000 triple quadruple mass spectrometer (Applied Biosystems; Thermo Fisher Scientific, Inc.) under an electrospray ionization negative mode (standard curves ranged from 1.00 to $4,000 \mathrm{ng} / \mathrm{ml} ; \mathrm{r}^{2}>0.99$ ). The lower limit of quantitation for CsA was $1.00 \mathrm{ng} / \mathrm{ml}$. The assay accuracy (\% bias), and precision (\% relative standard deviations) of the quality control samples were within $\pm 15 \%$.

Measurement of intestinal and hepatic mRNA expression levels. The expression levels of mRNA encoding CYP3A1, CYP3A2, UGT1A, OATP2B1 (small intestine only), OATP1B2 (liver only), P-gp, BCRP and MRP2 in the small intestine and liver were quantified by RT-qPCR. The tissues $\left(100 \mathrm{mg}\right.$ ) were homogenized in $1 \mathrm{ml} \mathrm{TRIzol}{ }^{\circledR}$ reagent. Total RNA was extracted according to the manufacturer's instructions. The RNA was quantified by the standard optical density (OD) 260 method (41). The $\mathrm{OD}_{260} / \mathrm{OD}_{280}$ ratio for each RNA sample ranged from 1.8 to 2.2. Subsequently, RNA was converted to cDNA using the high-capacity First Strand cDNA Synthesis kit (Toyobo, Co., Ltd.), according to the manufacturer's instructions. qPCR was performed using THUNDERBIRD ${ }^{\circledR}$ SYBR $^{\circledR}$ qPCR Mix (Toyobo, Co., Ltd.) and a StepOnePlus Real-Time PCR System (Applied Biosystems; Thermo Fisher Scientific, Inc.). Specific primers for Cyp3a1, Cyp3a2, Ugtla, solute carrier organic anion transporter family member (Slco) 2b1, Slcolb2, multi-drug resistance 1 (Mdrl), Bcrp, Mrp2 and the housekeeping gene $\beta$-actin were synthesized by Invitrogen; Thermo Fisher Scientific, Inc. and are listed in Table I. The PCR cycling protocol consisted of one cycle of $1 \mathrm{~min}$ at $95^{\circ} \mathrm{C}$, followed by 40 cycles of denaturation for $15 \mathrm{sec}$ at $95^{\circ} \mathrm{C}$, annealing for
$20 \mathrm{sec}$ at $58^{\circ} \mathrm{C}$ and extension for $20 \mathrm{sec}$ at $72^{\circ} \mathrm{C}$. For the final cycle only, the duration of the elongation step was $5 \mathrm{~min}$. The relative mRNA expression levels were calculated using the $2^{-\Delta \Delta \mathrm{Cq}}$ method (42).

Measurement of intestinal and hepatic protein expression levels. The protein expression levels of CYP3A1, CYP3A2, UGT1A, OATP2B1 (small intestine only), OATP1B2 (liver only), P-gp, BCRP and MRP2 in the small intestine and liver were analyzed by western blotting. The small intestine and liver samples were homogenized in 10X ice-cold buffer consisting of $10 \mathrm{mM}$ Tris- $\mathrm{HCl}$ ( $\mathrm{pH} 7.5), 250 \mathrm{mM}$ sucrose, $1 \mathrm{mM}$ phenylmethylsulfonyl fluoride and protease inhibitor cocktail (Sigma-Aldrich), and centrifuged at $12,000 \mathrm{x} \mathrm{g}$ for $5 \mathrm{~min}$ at $4^{\circ} \mathrm{C}$. The supernatants were stored at $-80^{\circ} \mathrm{C}$ until analysis. Protein concentrations were determined using the BioRad Protein Assay (Bio-Rad Laboratories, Inc., Hercules, CA, USA). Protein samples $(40 \mu \mathrm{g})$ were loaded onto 8-20\% SDS-PAGE gels and subjected to electrophoresis at $120 \mathrm{~V}$ for $90 \mathrm{~min}$. The proteins were transferred to polyvinylidene difluoride membranes (Merck Millipore, Darmstadt, Germany). The membranes were blocked for $1 \mathrm{~h}$ with Tris-buffered saline (TBS) with $0.1 \%$ Tween-20 (TBST) containing 5\% skim milk and incubated with primary antibody overnight at $4{ }^{\circ} \mathrm{C}$. Membranes were subsequently washed three times with TBST, and incubated with horseradish peroxidase (HRP)-conjugated secondary antibody $(1: 10,000)$ for $30 \mathrm{~min}$ at room temperature. The following primary antibodies were purchased from Santa Cruz Biotechnology, Inc. (Dallas, TX, USA): mouse anti-CYP3A1 monoclonal antibody (1:200; sc-53246), mouse anti-P-gp monoclonal antibody (1:500; sc-71557), rabbit anti-BCRP polyclonal antibody (1:500; sc-25822), rabbit anti-MRP2 polyclonal antibody (1:500; sc-20766) and mouse anti- $\beta$-actin monoclonal antibody (1:5,000; TDY051). Additional antibodies purchased from Abcam (Cambridge, MA, USA) were: rabbit anti-UGT1A polyclonal antibody (1:1,000; ab194697) and rabbit anti-OATP2B1 polyclonal antibody (1:1,000; sc-376904). Rabbit anti-CYP3A2 polyclonal antibody (1:500; AB1276) was supplied by Merck Millipore. Secondary antibodies were goat 
anti-mouse IgG-HRP $(1: 10,000 ; 074-1806)$ and goat anti-rabbit IgG-HRP $(1: 10,000 ; 074-1506)$, which were purchased from Santa Cruz Biotechnology, Inc. Protein bands were visualized using Enhanced chemiluminescence plus western blotting detection system (GE Healthcare Life Sciences, Chalfont, UK) followed by exposure to Kodak films (Kodak, Rochester, NY, USA) and densitometry analyses (Kodak 1D3 image analysis software version 3.6.1; Kodak). Results were normalized relative to $\beta$-actin expression.

Pharmacokinetic analysis. The plasma concentration data were analyzed by a non-compartmental method using Drug and Statistics software version 3.0 (Mathematical Pharmacology Professional Committee of China, Shanghai, China). The elimination rate constant $\left(\mathrm{K}_{\mathrm{el}}\right)$ was calculated by log-linear regression of CsA data during the elimination phase. The terminal half-life $\left(\mathrm{t}_{1} / 2\right)$ was calculated by $0.693 / \mathrm{K}_{\mathrm{el}}$. The peak plasma concentration $\left(\mathrm{C}_{\max }\right)$ and time to reach peak plasma concentration $\left(T_{\max }\right)$ of CsA in plasma were derived directly from the concentration-time curve. The area under the plasma concentration-time curve $\left(\mathrm{AUC}_{0-\mathrm{t}}\right)$ from time zero to the time of last measured concentration $\left(\mathrm{C}_{\text {last }}\right)$ was calculated by the linear trapezoidal rule. The AUC from zero to infinity $\left(\mathrm{AUC}_{0-\infty}\right)$ was obtained by the addition of $\mathrm{AUC}_{0-\mathrm{t}}$ and the extrapolated area determined by $\mathrm{C}_{\mathrm{last}} / \mathrm{K}_{\mathrm{el}}$. The mean residence time (MRT) was calculated as MRT=AUMC/AUC, where AUMC represented the area under the first moment vs. time curve, calculated in a similar fashion to the AUC.

Statistical analysis. Statistical analyses were performed with GraphPad Prism version 6.0 (GraphPad Software, Inc., La Jolla, CA, USA). Unpaired Student's $t$ tests were performed for comparison between independent groups. The influences of Que on changes in mRNA and protein expression levels, as well as pharmacokinetic parameters of CsA were evaluated by paired Student's $t$ tests. For multiple comparisons, one-way analysis of variance (ANOVA) followed by Tukey's or Dunnett's post hoc test was performed for each group. All tests were two-tailed and $\mathrm{P}<0.05$ was considered to indicate a statistically significant difference. Data are presented as the mean \pm standard deviation.

\section{Results}

Effect of Que on CsA pharmacokinetic. Mean plasma concentration-time profiles of CsA in rats following oral administration of $10 \mathrm{mg} / \mathrm{kg}$ CsA in the presence or absence of Que $(25,50$ or $100 \mathrm{mg} / \mathrm{kg}$ ) are presented in Fig. 1; the corresponding pharmacokinetic parameters are presented in Table II. The presence of Que significantly altered the pharmacokinetic parameters of CsA. $\mathrm{C}_{\max }$ of CsA in the absence of Que on day 1 was $2412.66 \pm 544.85 \mathrm{ng} / \mathrm{ml}(\mathrm{n}=24)$, while that of CsA in the Que-treated rats decreased by 46 $(\mathrm{P}=0.0094), 50(\mathrm{P}=0.0175)$ and $47 \%(\mathrm{P}=0.0015)$ in the low-, moderate- and high-dose groups, respectively (day $9, \mathrm{n}=8$ each group). In addition, $\mathrm{AUC}_{0-\mathrm{t}}$ and $\mathrm{AUC}_{0-\infty}$ of $\mathrm{CsA}$ in Que-treated rats decreased, by $21(\mathrm{P}=0.3392)$ and $16 \%$ $(\mathrm{P}=0.5694), 30(\mathrm{P}=0.2567)$ and $33 \%(\mathrm{P}=0.4101)$, and 33 $(\mathrm{P}=0.0028)$ and $34 \%(\mathrm{P}=0.0036)$, respectively. Furthermore, Que-treated rats exhibited significantly increased $\mathrm{MRT}_{0-\mathrm{t}}$

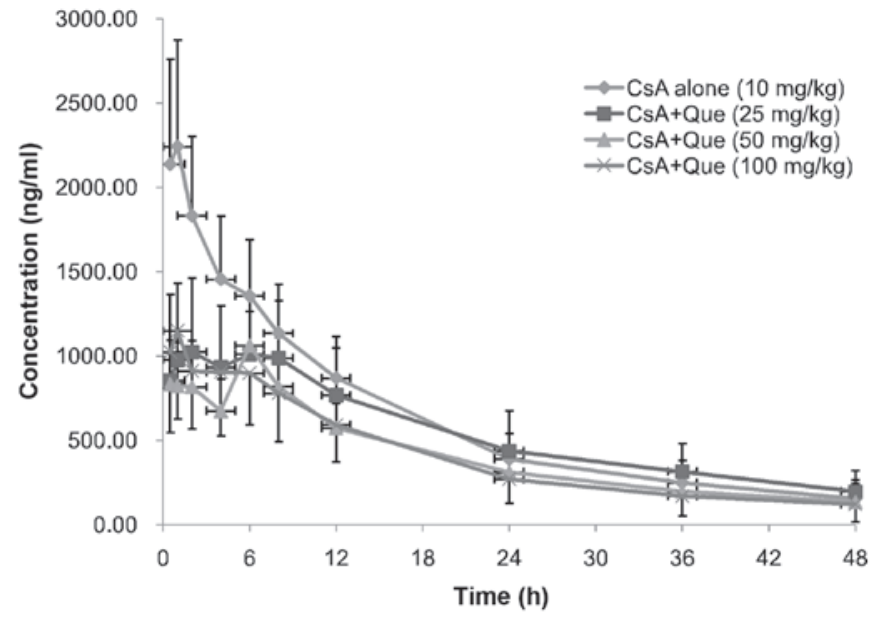

Figure 1. Mean plasma concentration-time profiles of CsA. On day 1, the rats received a single oral dose of CsA $(10 \mathrm{mg} / \mathrm{kg})$ alone. From days 3 to 8, all rats assigned to the Que-treatment groups were gavaged with 25, 50 or $100 \mathrm{mg} / \mathrm{kg} /$ day of Que for 6 consecutive days. On day 9, animals were pretreated with the relevant dosage of Que $0.5 \mathrm{~h}$ prior to the final dose of CsA (10 mg/kg), and blood samples were collected at various time points for pharmacokinetic analysis. Data are presented as the mean \pm standard deviation for each data point (Que-treated groups, $n=8$; CsA alone group, $n=24$ ). CsA, cyclosporine; Que, quercetin.

values compared with the control rats, increasing by 16 $(\mathrm{P}=0.0426), 19(\mathrm{P}=0.0458)$, and 9\% $(\mathrm{P}=0.0180)$ in the low-, moderate- and high-dose groups, respectively. However, there were no significant differences in $\mathrm{C}_{\max }(\mathrm{P}=0.6562), \mathrm{AUC}_{0-\mathrm{t}}$ $(\mathrm{P}=0.3087), \mathrm{AUC}_{0-\infty}(\mathrm{P}=0.2197)$ and $\mathrm{MRT}_{0-\mathrm{t}}(\mathrm{P}=0.1498)$ between the three Que treatment groups, or in the $\mathrm{T}_{\max }$ $(\mathrm{P}=0.2359), \mathrm{CL} / \mathrm{F}(\mathrm{P}=0.3325)$ and $\mathrm{t}_{1} / 2(\mathrm{P}=0.0540)$ of $\mathrm{CsA}$ between Que-treated and non-treated groups.

mRNA expression levels of DMEs and DTs in the small intestine and liver. The intestinal and hepatic mRNA encoding CYP3A1, CYP3A2, UGT1A, OATP2B1 (small intestine only), OATP1B2 (liver only), P-gp, BCRP and MRP2 were measured by RT-PCR analysis using intestinal and hepatic RNA prepared from rats (Fig. 2).

mRNA expression levels of Cyp $3 a 1$ and Cyp $3 a 2$. As presented in Fig. 2A and B, a dose-dependent decrease $(\mathrm{P}=0.0099$ and $\mathrm{P}<0.0001$, respectively) was observed in the intestinal mRNA expression levels of Cyp3a1 and Cyp $3 a 2$ in Que-WOC rats when compared to the control (vehicle) group, by 45 and $61 \%$ $(\mathrm{P}=0.0033$ and $\mathrm{P}=0.0006$, respectively), 83 and $70 \%(\mathrm{P}<0.0001$ and $\mathrm{P}=0.0004$, respectively), and 88 and $90 \%(\mathrm{P}<0.0001$ and $\mathrm{P}=0.0001$, respectively) in the low-, moderate- and high-dose groups, respectively. By contrast, CsA treatment increased the intestinal mRNA expression levels of Cyp3a1 and Cyp $3 a 2$ by $90(\mathrm{P}=0.0008)$ and $63 \%(\mathrm{P}=0.0022)$. When compared with CsA treatment alone, a dose-dependent decrease $(\mathrm{P}=0.0324$ and $\mathrm{P}<0.0001$, respectively) was observed in the intestinal mRNA expression levels of Cyp3a1 and Cyp $3 a 2$ in Que-WC rats, by 46 and $58 \%(\mathrm{P}=0.0006$ and $\mathrm{P}=0.0002$, respectively), 83 and $71 \%(\mathrm{P}<0.0001$ and $\mathrm{P}<0.0001$, respectively), and 81 and $88 \%(\mathrm{P}<0.0001$ and $\mathrm{P}<0.0001$, respectively) in the low-, moderate- and high-dose Que co-administration groups, respectively. 


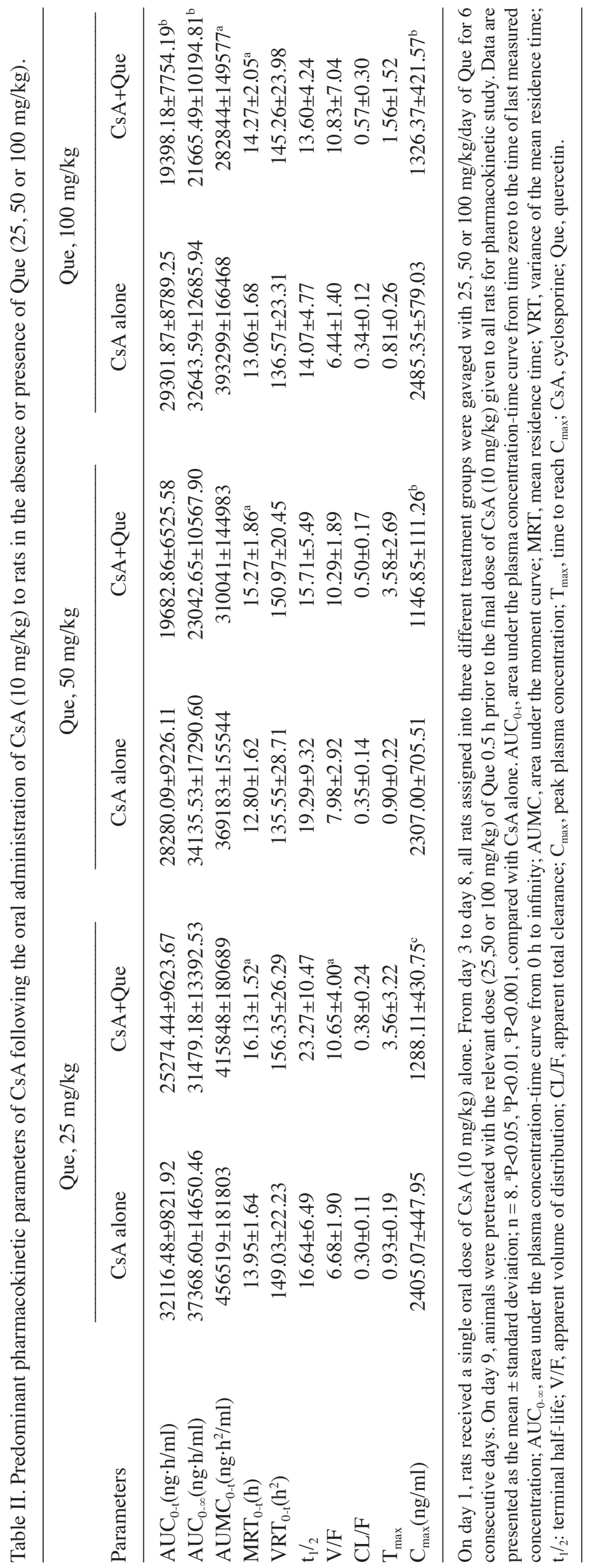


Similarly, in the liver, a dose-dependent decrease $(\mathrm{P}=0.0048$ and $\mathrm{P}=0.0002$, respectively) was observed in the mRNA expression levels of Cyp3al and Cyp3a2 in Que-WOC rats when compared to the control group, by 37 and $21 \%(\mathrm{P}=0.0092$ and $\mathrm{P}=0.0036$, respectively), 86 and $37 \%$ $(\mathrm{P}<0.0001)$, and 98 and $49 \%(\mathrm{P}<0.0001)$ in the respective treatment groups. Contrasting with the small intestine, the hepatic mRNA expression level of Cyp3al was not significantly influenced by $\mathrm{CsA}$ treatment $(\mathrm{P}=0.0563)$; however, there was a significant rise $(23 \% ; \mathrm{P}=0.0083)$ in Cyp3a2. When compared to CsA treatment alone, Que-WC treatment led to a decrease in the hepatic mRNA expression levels of Cyp3al and Cyp3a2, by $31(\mathrm{P}=0.0206)$ and $16 \%(\mathrm{P}=0.0398), 77(\mathrm{P}<0.0001)$ and $48 \%(\mathrm{P}=0.0002)$, and $65(\mathrm{P}<0.0001)$ and $57 \%(\mathrm{P}<0.0001)$ in the respective treatment groups. These results revealed that the mRNA expression levels of Cyp3al and Cyp3a2 were inhibited by Que to a similar extent in the small intestine and liver.

mRNA expression levels of Ugtlal. The mRNA expression of Ugtlal in the Que-WOC rats was significantly decreased in a dose-dependent manner $(\mathrm{P}=0.0070)$ by $20(\mathrm{P}=0.0045), 76$ $(\mathrm{P}<0.0001)$ and $84 \%(\mathrm{P}<0.0001)$ in the small intestine, and by 41,81 and $92 \%$ in the liver $(\mathrm{P}<0.0001)$, in the respective treatment groups (Fig. 2C). CsA treatment led to a significant increase $(109 \% ; \mathrm{P}=0.0002)$ in the intestinal mRNA expression level of Ugtlal compared with the control group, while the hepatic mRNA expression level of Ugtlal was not significantly influenced by CsA treatment $(\mathrm{P}=0.0970)$. Similarly, when compared to CsA treatment alone, Que-WC treatment led to a dose-dependent decrease $(\mathrm{P}=0.0061$ and $\mathrm{P}=0.0005$, respectively) in the intestinal and hepatic mRNA expression levels of Ugtlal, by $32(\mathrm{P}=0.0062)$ and $28 \%(\mathrm{P}=0.0088), 76$ $(\mathrm{P}<0.0001)$ and $71 \%(\mathrm{P}<0.0001)$, and $84(\mathrm{P}<0.0001)$ and $92 \%$ $(\mathrm{P}<0.0001)$ in the respective treatment groups.

$m R N A$ expression levels of Slco2b1/Slcolb2. As presented in Fig. 2D, a dose-dependent decrease $(\mathrm{P}=0.0010$ and $\mathrm{P}=0.0052$, respectively) was observed in the mRNA expression levels of Slco2bl in the small intestine and Slcolb2 in the liver of Que-WOC rats when compared to the control (vehicle) group, by $84(\mathrm{P}<0.0001)$ and $79 \%(\mathrm{P}=0.0005), 92(\mathrm{P}<0.0001)$ and $92 \%(\mathrm{P}=0.0002)$, and $97(\mathrm{P}<0.0001)$ and $95 \%(\mathrm{P}=0.0002)$ in the low-, moderate- and high-dose groups, respectively. By contrast, CsA treatment led to a significant increase in the mRNA expression levels of Slco $2 b 1$ in the small intestine (54\%; $\mathrm{P}=0.0057)$ and Slcolb2 in the liver $(29 \% ; \mathrm{P}=0.0292)$ compared with the control. Similarly, when compared with CsA treatment, Que-WC treatment led to a marked decrease in the intestinal Slco2b1 and hepatic Slcolb2 mRNA expression levels, by $66(\mathrm{P}=0.0087)$ and $72 \%(\mathrm{P}<0.0001), 92(\mathrm{P}=0.0001)$ and $90 \%(\mathrm{P}<0.0001)$, and $92(\mathrm{P}=0.0001)$ and $94 \%(\mathrm{P}<0.0001)$ in the respective treatment groups. These results revealed that Que had a potent inhibitory effect on the intestinal Slco2bl and hepatic Slcolb2 mRNA expression levels.

mRNA expression levels of Mdrl. In the small intestine, as presented in Fig. 2E, moderate- and high-dose Que-WOC treatment led to an increase in the mRNA expression levels of $M d r l$ by $75(\mathrm{P}=0.0008)$ and $80 \%(\mathrm{P}=0.0004)$, respectively, compared with the control group, while low-dose treatment did not produce a significant effect $(\mathrm{P}=0.2312)$. Similarly, in the Que-WC rats, moderate- and high-dose Que co-treatment led to a decrease in the mRNA expression level of $M d r 1$ by $78 \%$ when compared with CsA treatment alone $(\mathrm{P}=0.0033$ and $\mathrm{P}=0.0034$, respectively), while low-dose treatment did not produce a significant effect $(\mathrm{P}=0.2661)$. By contrast, CsA treatment increased the mRNA expression levels of $M d r l$ in the small intestine and liver, by $74(\mathrm{P}=0.0305)$ and $19 \%(\mathrm{P}=0.0239)$, respectively.

In the liver, a dose-dependent decrease $(\mathrm{P}=0.0066)$ was observed in the mRNA expression levels of $M d r 1$ in Que-WOC rats when compared with the control (vehicle) group, by 64,87 and $91 \%$ in the respective treatment groups $(\mathrm{P}<0.0001)$. Similarly, when compared with CsA treatment alone, Que-WC treatment led to a decrease in the hepatic mRNA expression levels of $M d r l$, by 68, 68 and $90 \%$ in the respective treatment groups $(\mathrm{P}<0.0001)$.

mRNA expression levels of Bcrp. A dose-dependent decrease $(\mathrm{P}<0.0001$ and $\mathrm{P}=0.0002$, respectively) was observed in the mRNA expression levels of Bcrp in the small intestine and liver of Que-WOC rats when compared to the control (vehicle) group, by 46 and 55\%, 70 and 77\%, and 92 and $88 \%$ in the respective treatment groups $(\mathrm{P}<0.0001$, Fig. $2 \mathrm{~F})$. CsA treatment led to a significant increase in the intestinal mRNA expression levels of Bcrp (75\%; $\mathrm{P}=0.0007)$, while in the liver Bcrp was not significantly influenced by CsA treatment $(\mathrm{P}=0.1736)$. When compared with CsA treatment alone, Que-WC treatment led to a dose-dependent decrease $(\mathrm{P}<0.0001)$ in the Bcrp mRNA expression levels, by 50 $(\mathrm{P}=0.0002)$ and $68 \%(\mathrm{P}=0.0008), 68(\mathrm{P}<0.0001)$ and $77 \%$ $(\mathrm{P}=0.0004)$, and $91(\mathrm{P}<0.0001)$ and $89 \%(\mathrm{P}=0.0002<0.001)$ in the respective treatment groups. These results revealed that the mRNA expression levels of Bcrp were inhibited by Que to a similar extent in the small intestine and liver.

mRNA expression levels of Mrp2. As presented in Fig. 2G, a dose-dependent decrease $(\mathrm{P}<0.0001)$ was observed in the mRNA expression levels of Mrp2 in the small intestine and liver of Que-WOC rats compared with the control (vehicle) group, by 45 and 45\%, 69 and 52\%, and 96 and $98 \%$ in the respective treatment groups $(\mathrm{P}<0.0001)$. CsA treatment led to a significant increase in the intestinal mRNA expression levels of Mrp2 (65\%; $\mathrm{P}=0.0025)$, while in the liver Mrp2 was not significantly influenced by $\mathrm{CsA}$ treatment $(\mathrm{P}=0.2855)$. When compared with CsA treatment alone, Que-WC treatment led to a dose-dependent decrease $(\mathrm{P}<0.0010 .05)$ in the Mrp2 mRNA expression levels in the small intestine and liver, by $48(\mathrm{P}=0.0015)$ and $38 \%(\mathrm{P}=0.0006), 68(\mathrm{P}=0.0004)$ and $36 \%(\mathrm{P}<0.001)$, and $85(\mathrm{P}=0.0002)$ and $99 \%(\mathrm{P}<0.0001)$ in the respective treatment groups.

Taken together, these results revealed that the mRNA expression levels of the investigated DMEs and DTs were inhibited by Que in a dose-dependent manner, and to a similar extent in the small intestine and liver. In addition, when compared with CsA treatment alone, Que-WC treatment demonstrated a dose-dependent inhibitory effect in the small intestine and liver of the respective treatment groups.

Protein expression levels of DMEs and DTs in the small intestine and liver. The intestinal and hepatic proteins 
A

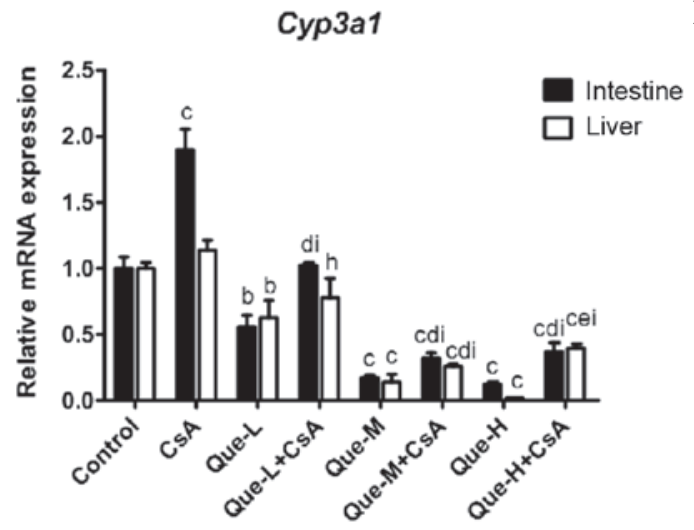

C

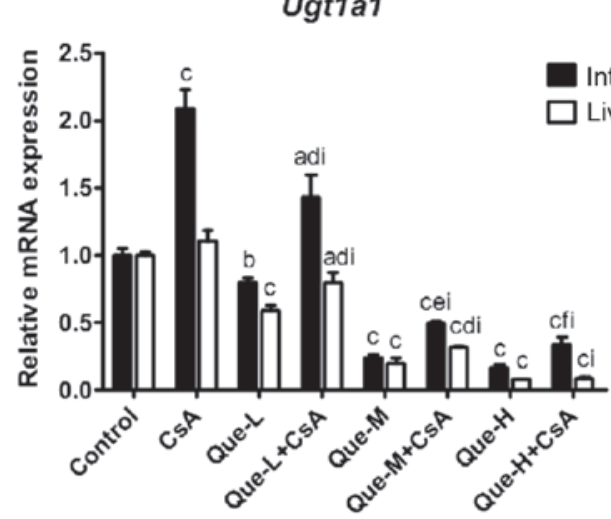

$\mathbf{E}$

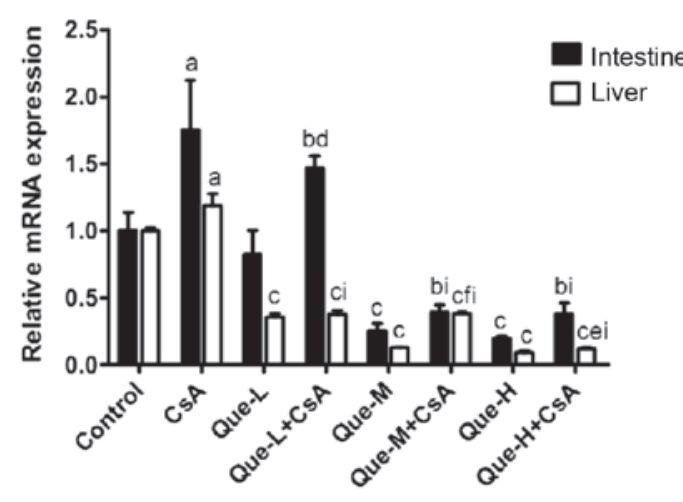

B

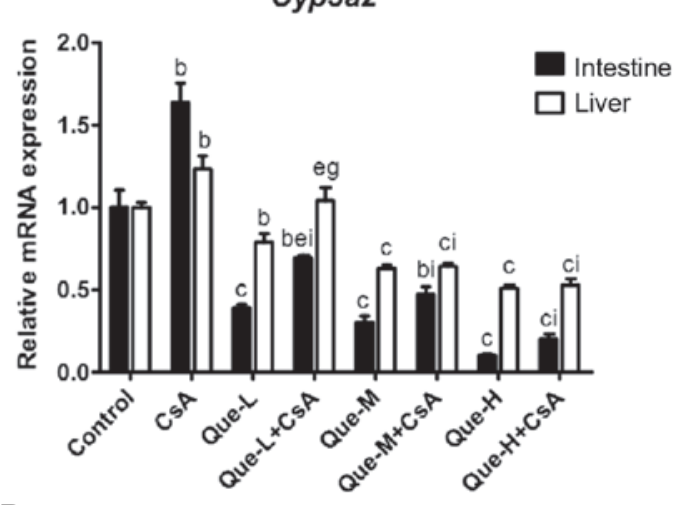

D

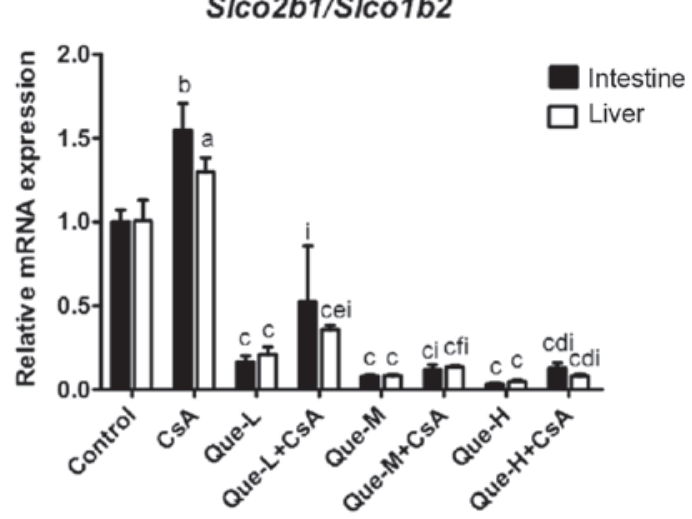

F

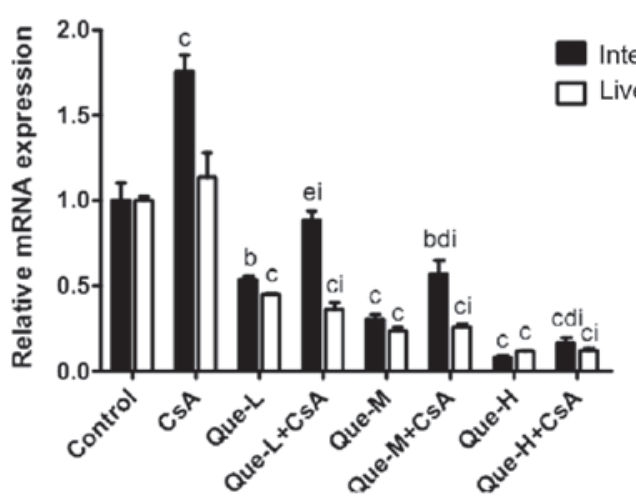

Mrp2

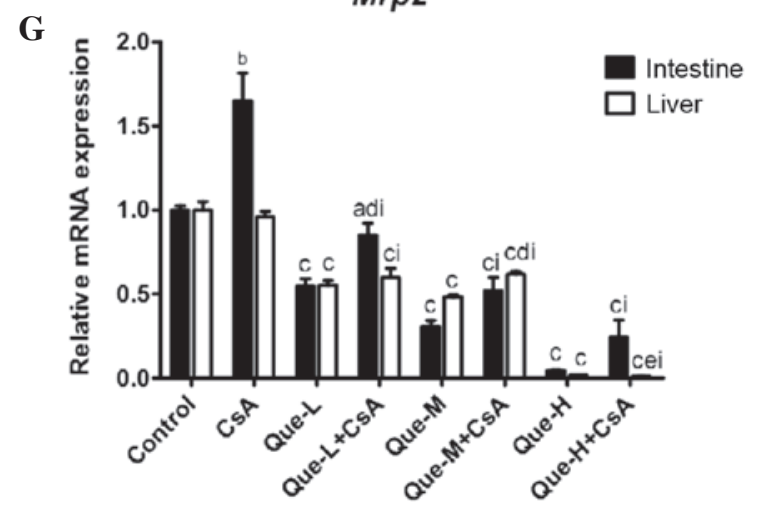

Figure 2. Effect of Que on the intestinal and hepatic mRNA expression levels of CYP3A1, CYP3A2, UGT1A, SLCO2B1, SLCO1B2, MDR1, BCRP and MRP2. In rats of the control, CsA treatment, and Que treatment without (Que-WOC) and with (Que-WC) CsA for 7 consecutive days groups, the mRNA expression levels were measured by reverse transcription-quantitative polymerase chain reaction and calculated as expression levels relative to the control using the $2^{-\triangle \Delta C q}$ method. mRNA expression levels of (A) Cyp3a1, (B) Cyp3a2, (C) Ugt1a1, (D) Slco2b1/Slcolb2, (E) Mdr1, (F) Bcrp and (G) Mrp2 were measured in the small intestine and liver of rats. $\beta$-actin was used as a loading control. Data are presented as the mean \pm standard deviation $(\mathrm{n}=3)$. ${ }^{\mathrm{a}}<0.05$, ${ }^{\mathrm{b}} \mathrm{P}<0.01$ and ${ }^{\mathrm{C}} \mathrm{P}<0.001$, compared with the control; ${ }^{\mathrm{d}} \mathrm{P}<0.05,{ }^{\mathrm{e}} \mathrm{P}<0.01$, and ${ }^{\mathrm{f}} \mathrm{P}<0.001$, compared to the Que-WOC group; ${ }^{\text {g }} \mathrm{P}<0.05,{ }^{\mathrm{h}} \mathrm{P}<0.01$, and ${ }^{\mathrm{i}} \mathrm{P}<0.001$, compared to the CsA treatment alone group. Que-L, Que low dose (25 mg/kg); Que-M, Que moderate dose (50 mg/kg); Que-H, Que high dose (100 mg/kg); CsA, cyclosporine; Que, quercetin; Cyp, cytochrome P; Ugtla1, UDP glucuronosyltransferase family 1 member A complex locus; Slco, solute carrier organic anion transporter family member; Mdr1, multi-drug resistance 1; Bcrp, breast cancer resistance protein; Mrp2, multidrug resistance-associated protein 2. 
A

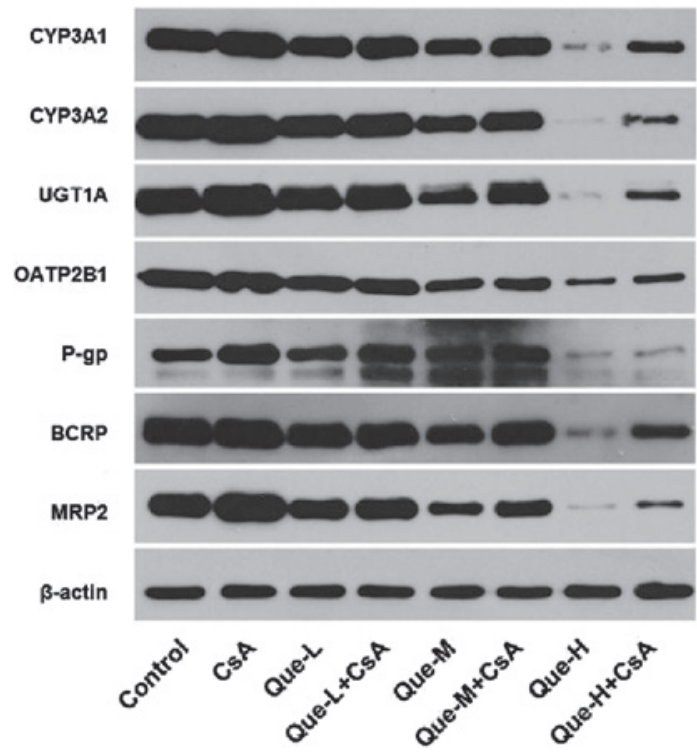

B

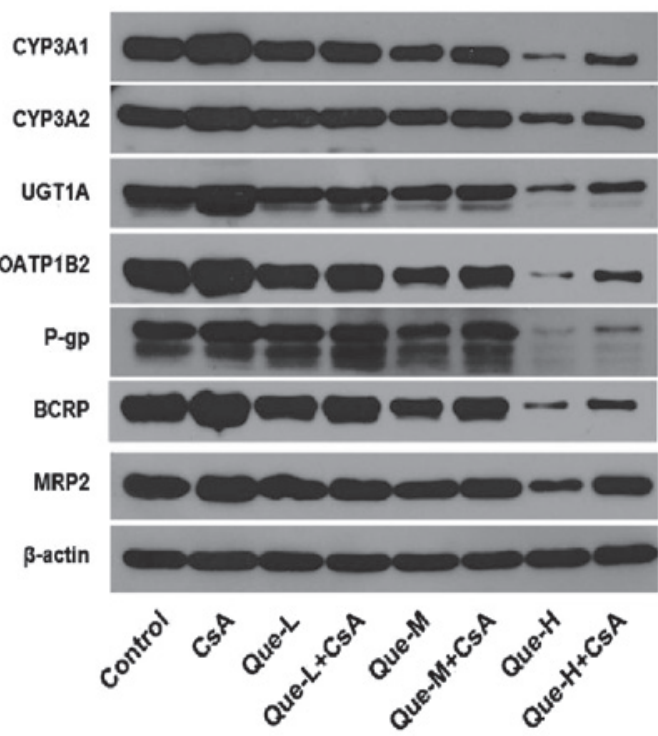

Figure 3. Effect of Que on the intestinal and hepatic protein expression levels of CYP3A1, CYP3A2, UGT1A, OATP2B1, OATP1B2, P-gp, BCRP and MRP2 assessed by western blotting. In rats of the control, CsA treatment, and Que treatment without (Que-WOC) or with (Que-WC) CsA for 7 consecutive days groups, western blotting analysis was performed and $\beta$-actin was used as a loading control. (A) Image of western blotting results in the small intestine (B) Image of western blotting results in the liver. Que-L, Que low dose (25 mg/kg); Que-M, Que moderate dose (50 mg/kg); Que-H, Que high dose (100 mg/kg); CsA, cyclosporine; Que, quercetin; CYP, cytochrome P; UGT1A1, UDP glucuronosyltransferase family 1 member A; OATP, organic anion-transporting polypeptide; P-gp, P-glycoprotein; BCRP, breast cancer resistance protein; MRP2, multidrug resistance-associated protein 2.

CYP3A1, CYP3A2, UGT1A, OATP2B1, OATP1B2, P-gp, BCRP and MRP2 were measured by western blotting analysis in all treated rats (Fig. 3). Images of western blots performed on the small intestine and liver of rats are presented in Fig. 3A and $\mathrm{B}$ respectively. Quantification of western blots is presented in Fig. 4.

Protein expression levels of CYP3A1 and CYP3A2. As presented in Fig. 4A and B, a dose-dependent decrease $(\mathrm{P}<0.0001)$ was observed in the intestinal protein expression levels of CYP3A1 and CYP3A2 in Que-WOC rats when compared with the control (vehicle) group, by $17(\mathrm{P}=0.1181)$ and $14 \%(\mathrm{P}=0.3328)$, $45(\mathrm{P}=0.0078)$ and $40 \%(\mathrm{P}=0.0270)$, and $91(\mathrm{P}=0.0003)$ and $95 \%(\mathrm{P}=0.0007)$ in the low-, moderate- and high-dose groups, respectively. Contrasting with the mRNA expression level results, CsA treatment did not alter the protein expression levels of CYP3A1 or CYP3A2 in the small intestine or liver. This may be due to the high basal level of CYP3A, meaning an additional increase in mRNA expression levels would not result in a significant change in protein expression levels. When compared with CsA treatment alone, a dose-dependent decrease $(\mathrm{P}<0.001)$ was observed in the intestinal protein expression levels of CYP3A1 and CYP3A2 in Que-WC rats, by $22(\mathrm{P}=0.0121)$ and $18 \%(\mathrm{P}=0.1467), 38(\mathrm{P}=0.0055)$ and $35 \%(\mathrm{P}=0.0241)$, and 67 $(\mathrm{P}<0.0001)$ and $71 \%(\mathrm{P}=0.0006)$ in the low-, moderate- and high-dose Que co-administration groups, respectively.

High-dose Que treatment led to an decrease in the hepatic protein expression levels of CYP3A1 and CYP3A2 by 70 $(\mathrm{P}=0.0022)$ and $73 \%(\mathrm{P}=0.0075)$, respectively, compared with the control, while moderate- $(\mathrm{P}=0.0501$ and $\mathrm{P}=0.0867$, respectively $)$ and low-dose $(\mathrm{P}=0.1219$ and $\mathrm{P}=0.2661$, respectively) treatment did not produce significant effects. However, a dose-dependent decrease $(\mathrm{P}=0.0006)$ was observed in Que-WOC rats. Similarly, when compared with CsA treatment alone, only in the high-dose co-administration groups was a significant decrease observed in the hepatic protein expression levels of CYP3A1 and CYP3A2 in Que-WC rats, by $56(\mathrm{P}=0.0071)$ and $54 \%(\mathrm{P}=0.0163)$, respectively.

Protein expression levels of UGT1A1. When compared with the control, the protein expression levels of UGT1A1 in the Que-WOC rats was significantly decreased in a dose-dependent manner by $12(\mathrm{P}=0.0888), 41(\mathrm{P}=0.0024)$ and $91 \%(\mathrm{P}=0.0001)$ in the small intestine, and by $16(\mathrm{P}=0.6453), 42(\mathrm{P}=0.2090)$ and $87 \%(\mathrm{P}=0.0231)$ in the liver (Fig. $4 \mathrm{C})$. Similar to the mRNA expression level results, CsA treatment led to a significant increase in the intestinal protein expression level of UGT1A1 (27\%; $\mathrm{P}=0.0380)$ compared with the control group, while the hepatic protein expression level of UGT1A1 was not significantly influenced by CsA treatment $(\mathrm{P}=0.6597)$. Compared with CsA treatment, Que-WC treatment led to a dose-dependent decrease $(\mathrm{P}<0.0001)$ in the intestinal protein expression levels of UGT1A1, by $22(\mathrm{P}=0.0490), 39(\mathrm{P}=0.0079)$ and $74 \%(\mathrm{P}=0.0003)$ in the respective treatment groups. However, only high-dose Que-WC treatment led to a decrease in the hepatic protein expression levels of UGT1A1 $(72 \%$; $\mathrm{P}=0.0448)$ compared with CsA treatment alone, while low- and moderate-dose treatment did not produce significant effects $(\mathrm{P}=0.4835$ and $\mathrm{P}=0.1782$, respectively).

Protein expression levels of OATP2B1/OATP1B2. Similar to the mRNA results, a dose-dependent decrease $(\mathrm{P}<0.001)$ in the moderate- and high-dose groups was observed in the protein expression levels of OATP2B1 in the small intestine and OATP1B2 in the liver in Que-WOC rats when compared with the control (vehicle) group, by $43(\mathrm{P}=0.0282)$ and $48 \%$ 
$(\mathrm{P}=0.0222)$, and $76(\mathrm{P}=0.0031)$ and $86 \%(\mathrm{P}=0.0027)$, respectively, while low-dose treatment did not produce a significant effect ( $\mathrm{P}=0.1498$ and $\mathrm{P}=0.3482$, respectively; Fig. 4D). CsA treatment did not alter the protein expression levels of OATP2B1 and OATP1B2 in the small intestine and liver. Similarly, when compared with CsA treatment, only moderateand high-dose Que-WC treatment led to a marked decrease, by $42(\mathrm{P}=0.0297)$ and $38 \%(\mathrm{P}=0.0254)$, and $63(\mathrm{P}=0.0071)$ and $72 \%(\mathrm{P}=0.0028)$, respectively. When compared with the mRNA results, Que demonstrated a weak inhibitory effect on intestinal OATP2B1 and hepatic OATP1B2 protein expression.

Protein expression levels of P-gp. As presented in Fig. 4E, high-dose Que treatment led to a significant decrease in the intestinal and liver protein expression levels of P-gp by 81 $(\mathrm{P}=0.0059)$ and $84 \%(\mathrm{P}=0.0153)$, respectively, compared with the control group, while low- $(\mathrm{P}=0.7061$ and $\mathrm{P}=0.7554$, respectively) and moderate-dose $(\mathrm{P}=0.2448$ and $\mathrm{P}=0.0758$, respectively) treatment did not produce a significant effect. Similarly, only high-dose Que-WC treatment led to a marked decline in the intestinal and liver protein expression levels of $\mathrm{P}-\mathrm{gp}$ when compared with CsA treatment, by $83(\mathrm{P}=0.0108)$ and $76 \%(\mathrm{P}=0.0330)$, respectively.

Protein expression levels of BCRP. A dose-dependent decrease $(\mathrm{P}<0.0001)$ was observed in the protein expression levels of BCRP in the small intestine and liver of Que-WOC rats when compared with the control (vehicle) group, by 17 $(\mathrm{P}=0.2130)$ and $7 \%(\mathrm{P}=0.6968), 49(\mathrm{P}=0.0109)$ and $27 \%$ $(\mathrm{P}=0.1563)$, and $90(\mathrm{P}=0.0009)$ and $75 \%(\mathrm{P}=0.0072)$ in the respective treatment groups. When compared with $\mathrm{CsA}$ treatment alone, Que-WC treatment led to a dose-dependent decrease $(\mathrm{P}<0.001)$ in the BCRP protein expression levels, by $22(\mathrm{P}=0.0262)$ and $23 \%(\mathrm{P}=0.0841), 36(\mathrm{P}=0.0044)$ and $31 \%$ $(\mathrm{P}=0.0475)$, and $69(\mathrm{P}=0.0004)$ and $67 \%(\mathrm{P}=0.0015)$ in the respective treatment groups (Fig. $4 \mathrm{~F})$. Therefore, in the small intestine and liver the protein expression levels of BCRP were inhibited by Que to a similar extent.

Protein expression levels of MRP2.A dose-dependent decrease $(\mathrm{P}<0.0001)$ was observed in the protein expression levels of MRP2 in the small intestine and liver of Que-WOC rats compared with the control (vehicle) group, by $13(\mathrm{P}=0.0874)$ and $14 \%(\mathrm{P}=0.2608), 45(\mathrm{P}=0.0011)$ and $27 \%(\mathrm{P}=0.0693)$, and $93(\mathrm{P}<0.0001)$ and $58 \%(\mathrm{P}=0.0041)$ in the respective treatment groups. Similar to the mRNA expression level results, CsA treatment led to a significant increase in the intestinal protein expression level of MRP2 (45\%; $\mathrm{P}=0.0187)$, while in the liver MRP2 was not significantly influenced by CsA treatment $(\mathrm{P}=0.6103)$. When compared with CsA treatment, Que-WC treatment led to a dose-dependent decrease $(\mathrm{P}<0.0001$ and $\mathrm{P}=0.0260$, respectively) in MRP2 protein expression levels, by $32(\mathrm{P}=0.0164)$ and $22 \%(\mathrm{P}=0.0934), 52(\mathrm{P}=0.0023)$ and $23 \%$ $(\mathrm{P}=0.0776)$, and $82(\mathrm{P}=0.0004)$ and $35 \%(\mathrm{P}=0.0235)$ in the respective treatment groups (Fig. $4 \mathrm{G}$ ).

Taken together, these results revealed that the protein expression levels of the investigated DMEs and DTs were dose-dependently inhibited by Que to a similar extent in the small intestine and liver. However, in contrast to the mRNA expression level results, the low-dose $(25 \mathrm{mg} / \mathrm{kg}$ ) Que treatment did not demonstrate a significant inhibitory effect on the protein expression levels when compared with the control.

\section{Discussion}

Currently, flavonoid-drug interactions are gaining the attention of the scientific community, particularly with regard to clinical practice. Increasing evidence suggests that Que may interact with numerous xenobiotics. For example, Que has been demonstrated to increase the bioavailability of various drugs, including fexofenadine (43), rosiglitazone (44) and CsA (33) in humans; paclitaxel (45), valsartan (46), ranolazine (47), tamoxifen (48) and doxorubicin (49) in rats; and digoxin (50) in pigs. By contrast, Que decreased the bioavailability of talinolol (51) in humans, metoprolol (52) in rats, simvastatin (53) in pigs and CsA $(32,34-36)$ in pigs and rats. Therefore, the HDIs of Que co-administration with other drugs, as well as the effect of Que on CYP3A and P-gp, remain to be fully elucidated. To the best of our knowledge, this is the first report to systematically demonstrate the impact of multiple-dose administration of Que on DMEs and DTs in the small intestine and liver, as well as on the pharmacokinetics of CsA.

CsA is an immunosuppressant that is routinely used to prevent rejection of kidney, liver, heart and bone marrow transplants and in addition is used to treat various autoimmune diseases (27). Clinically, a supra-therapeutic CsA blood level may result in adverse effects including nephrotoxicity, hepatotoxicity and neurotoxicity (27). Conversely, a sub-therapeutic blood level may result in allograft rejection by transplant recipients (54). As CsA is effective within a narrow therapeutic index (37), a thorough understanding of its propensity for HDIs is required prior to co-administration with novel pharmacologic agents that may affect its efficacy.

CsA is primarily metabolized in the small intestine and liver by isoenzymes CYP3A4 and CYP3A5 $(27,55)$. In addition, UGT1A and 2B, P-gp and MRP2 are involved in CsA bioavailability (27-29). Numerous factors, including food ingestion, changes in gastric motility, diarrhea, diabetes and genetic polymorphism (56), may affect CsA metabolism and bioavailability, and information is required by clinicians and patients to prevent the inadvertent alteration of CsA serum levels. In addition, a leading cause of altered CsA metabolism is the co-administration of herbal medicines that affect the activity of DMEs or DTs, or alter their interactions with CsA, including ginkgo, St John's wort, ginger, ginseng, garlic and berberine $(2,37)$.

Besides the ameliorative effect of Que on CsA-induced nephrotoxicity and hepatotoxicity $(8,9)$, Que is known to affect the immune system $(40,57)$. Que has been reported to inhibit the production of IL-2 by human T cells in a dose-dependent manner (57), which may explain its immunosuppressive effects. Co-administration with CsA may therefore enhance immunosuppression.

In the present study, the pharmacokinetic interaction between Que and CsA was investigated in rats. Based on the ratio of surface area (human/rat), the doses of 25, 50 and $100 \mathrm{mg} / \mathrm{kg}$ were tested in rats in the present study, with the corresponding doses in humans being 250,500 and $1000 \mathrm{mg} / \mathrm{day}$. The findings of the present study demonstrated that concomitant oral admin- 
A

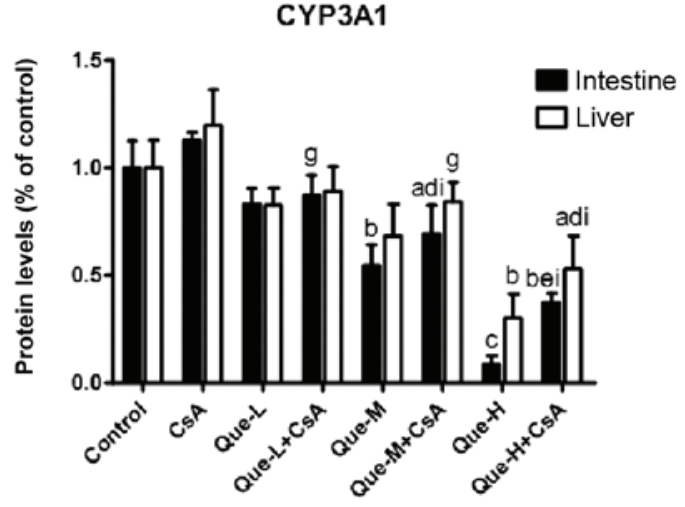

C

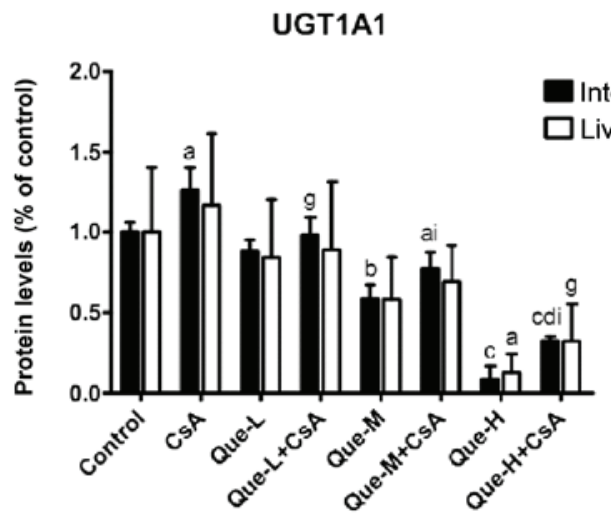

E

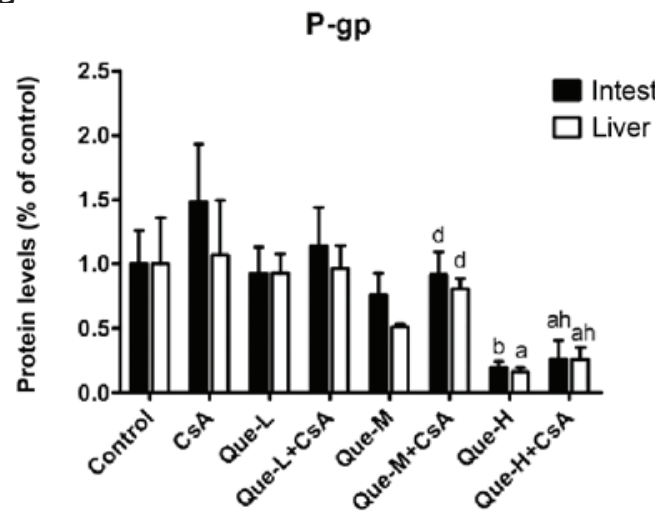

B

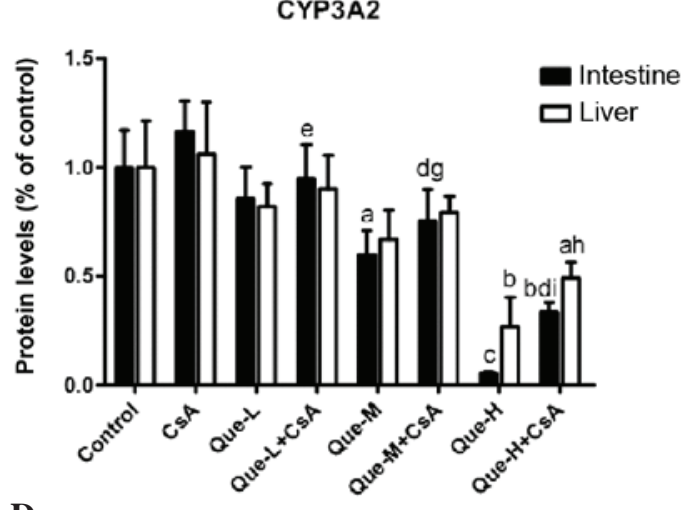

D

OATP2B1/OATP1B2

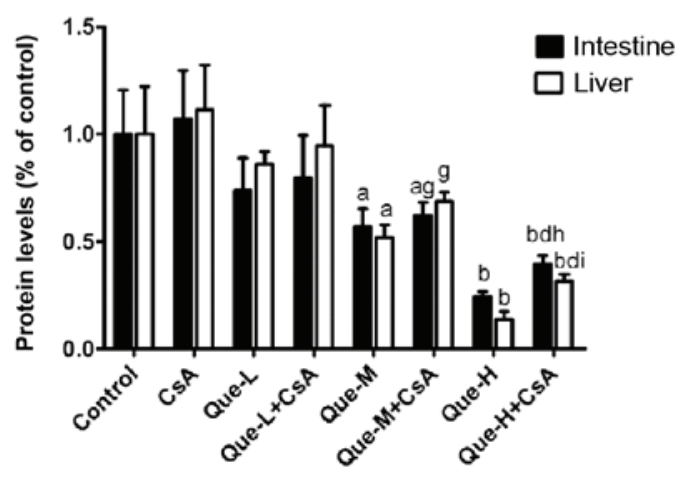

$\mathbf{F}$

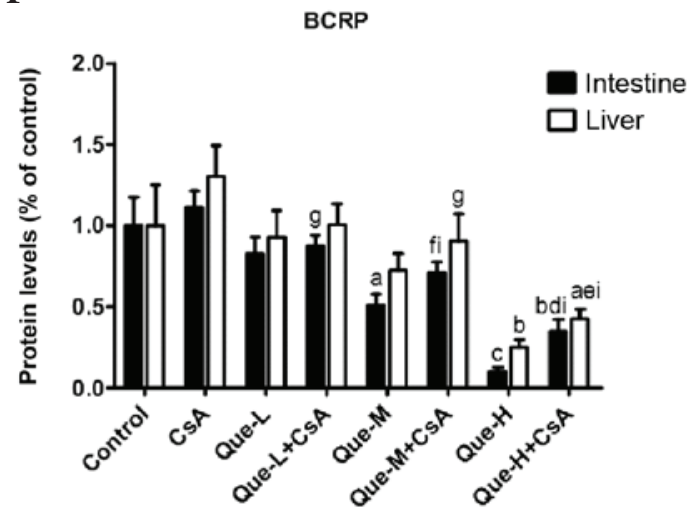

G

MRP2

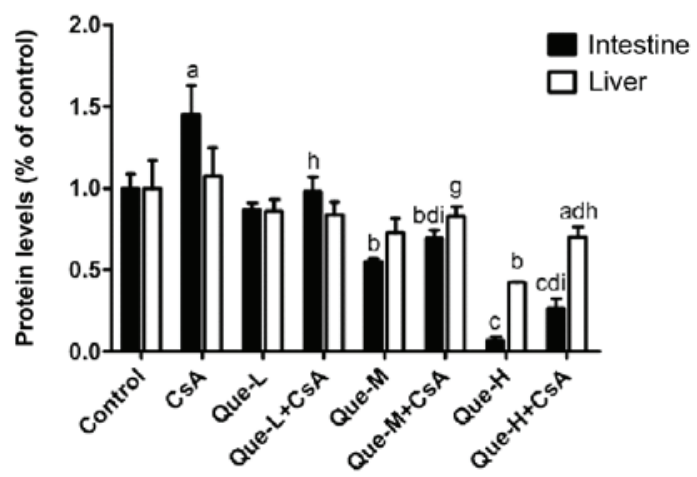

Figure 4. Quantification of the effect of Que on intestinal and hepatic protein expression levels of CYP3A1, CYP3A2, UGT1A, OATP2B1, OATP1B2, P-gp, BCRP and MRP2 assessed by western blotting. Quantification of western blotting results revealed the protein expression levels of (A) CYP3A1, (B) CYP3A2, (C) UGT1A, (D) OATP2B1/OATP1B2, (E) P-gp, (F) BCRP and (G) MRP2 measured in the small intestine and liver of rats. Data are presented as the mean \pm standard deviation $(\mathrm{n}=3) .{ }^{\mathrm{a}} \mathrm{P}<0.05$, ${ }^{\mathrm{b}} \mathrm{P}<0.01$ and ${ }^{\mathrm{c}} \mathrm{P}<0.001$, compared with the control; ${ }^{\mathrm{d}} \mathrm{P}<0.05$, ${ }^{\mathrm{e}} \mathrm{P}<0.01$ and ${ }^{\mathrm{f}} \mathrm{P}<0.001$, compared to the $\mathrm{Q}$ ue-WOC group; ${ }^{\mathrm{g}} \mathrm{P}<0.05,{ }^{\text {h}} \mathrm{P}<0.01$ and ${ }^{\mathrm{i}} \mathrm{P}<0.001$, compared to the CsA treatment group. Que-L, Que low dose (25 mg/kg); Que-M, Que moderate dose (50 mg/kg); Que-H, Que high dose (100 mg/kg); CsA, cyclosporine; Que, quercetin; CYP, cytochrome P; UGT1A, UDP glucuronosyltransferase family 1 member A; OATP, organic anion-transporting polypeptide; P-gp, P-glycoprotein; BCRP, breast cancer resistance protein; MRP2, multidrug resistance-associated protein 2. 
istration of Que $(25,50$ and $100 \mathrm{mg} / \mathrm{kg})$ dose-independently decreased $\mathrm{C}_{\max }$ by 46,50 , and $47 \%(\mathrm{P}<0.01)$. In addition, the $\mathrm{AUC}_{0-\mathrm{t}}$ and $\mathrm{AUC}_{0-\infty}$ of CsA was decreased, by 21 and $16 \%, 30$ and $33 \%$, and 33 and $34 \%(\mathrm{P}<0.01)$, respectively. Furthermore, Que-treated rats displayed significantly increased $\mathrm{MRT}_{0-\mathrm{t}}$ values compared with control rats, with dose-independent increases of 16,19 , and $9 \%(\mathrm{P}<0.05)$ in the low-, moderateand high-dose groups, respectively. Notably, there were no significant differences ( $\mathrm{P}>0.05$, by ANOVA) in $\mathrm{C}_{\max }, \mathrm{AUC}_{0-\mathrm{t}}$, $\mathrm{AUC}_{0-\infty}$ and $\mathrm{MRT}_{0-\mathrm{t}}$ among three-dose Que co-administration groups in the present study. Furthermore, no significant differences were observed in the $\mathrm{T}_{\max }, \mathrm{CL} / \mathrm{F}$ and $\mathrm{t}_{1} /{ }_{2}$ of CsA in the presence of Que when compared to CsA alone. Therefore, Que co-administration had a significant effect on CsA pharmacokinetics. These results were consistent with previous reports that the bioavailability of CsA in pigs and rats was reduced when Que or Que-derived products were co-administered (32,34-36). However, in a study by Choi et al (33), the AUC of CsA was increased by $18 \%$ when Que was orally co-administered (CsA $300 \mathrm{mg}$ plus Que $5 \mathrm{mg} / \mathrm{kg}$ ), by $36 \%$ when healthy male subjects received Que 30 min prior to CsA treatment, and by $47 \%$ when subjects received Que for three days prior to CsA treatment. This result contrasts with the results of the present study, which may be due to differences in the subjects, the methods of administration and the doses.

Furthermore, the results of the present study demonstrated that Que produced a significant inhibitory effect on the mRNA and protein expression of DMEs and DTs in the small intestine and liver of rats. Significantly, Que administered orally was capable of changing the mRNA and protein expression levels in the rat small intestine, and also modified the mRNA and protein expression levels in the rat liver. Notably, it was revealed that the mRNA expression levels of Cyp3a1, Cyp3a2, Ugtla1, Slco2b1, Slcolb2, Mdr1, Bcrp and Mrp2 were inhibited by Que in a dose-dependent manner $(\mathrm{P}<0.05)$ to a similar extent in the small intestine and liver. Additionally, in the small intestine and liver, when compared with CsA treatment alone, Que-WC treatment led to a dose-dependent decrease $(\mathrm{P}<0.05)$ in the mRNA expression levels in the low-, moderate- and high-dose co-administration groups. Notably, Que exerted a marked inhibitory effect on intestinal Slco2b1 and hepatic Slcolb2 mRNA expression, with reductions of 84 and 79\%, 92 and 92\%, and 97 and 95\% $(\mathrm{P}<0.001)$ in the low-, moderate- and high-dose groups, respectively. These effects should be further investigated in future research. Similarly, the protein expression levels of CYP3A1, CYP3A2, UGT1A, OATP2B1, OATP1B2, P-gp, BCRP and MRP2 were inhibited by Que in a dose-dependent manner $(\mathrm{P}<0.05)$ to a similar extent in the small intestine and liver. However, in contrast to the mRNA results, the low-dose $(25 \mathrm{mg} / \mathrm{kg})$ Que treatment did not produce a significant inhibitory effect on the protein expression levels when compared with the control. Notably, when compared with the potent inhibitory effect observed on mRNA expression levels, Que had a relatively weaker inhibitory effect on the protein expression levels.

The results of the present study were consistent with previous observations made in vitro and in vivo following co-treatment with Que $(18,20-22,26)$. However, evidence has not always been consistent $(16,17)$. Rats fed a diet containing
$1 \%$ Que demonstrated significantly increased activity of UGTs in the liver and, to a lesser extent, in the small intestine (58). Que significantly induced CYP3A activity and this induction was somewhat associated with the $C Y P 3 A 5$ genotype, being more prominent in $C Y P 3 A 5^{*} 1 /^{*} 1$ and $C Y P 3 A 5^{*} 1 /^{*} 3$ individuals (17). A previous study in healthy Chinese subjects demonstrated that Que significantly induced the activity of P-gp and this effect was more pronounced in individuals with the MDR1 3435 TT polymorphism (25). Thus, the effects of Que on P-gp remain to be fully understood (16). In a previous study of vincristine in MBEC4 cells, Que was observed to decrease the uptake of vincristine at low concentrations $(10 \mu \mathrm{M})$; however, it increased its uptake at high concentrations (50 $\mu \mathrm{M})(59)$. These biphasic in vitro results were supported by a study on ddY mice in vivo with co-administration of vincristine and Que at low $(0.1 \mathrm{mg} / \mathrm{kg})$ and high doses (1.0 mg/kg) (59). The biphasic effects were due to an alteration in the function of P-gp. At low concentrations, P-gp activity was increased as a result of enhanced phosphorylation, while at high concentrations P-gp was inhibited (59). A study identified that the major phase II metabolites of Que (including 3'-O-methylquercetin, 4'-O-methylquercetin, quercetin-3-O- $\beta$-glucoside, and quercetin-3-O-rhamnosylglucoside) inhibited MRP2 functions to a similar extent as the original compound (60). Que at a concentration of $25 \mu \mathrm{M}$ markedly induced mRNA and protein expression of BCRP in Caco-2 cells, possibly through regulation of the aryl hydrocarbon receptor (61). The majority of flavonoids have been demonstrated to acutely inhibit the activity of DMEs and DTs; however, chronically, DMEs and DTs had enhanced expression and/or activity (16). Aside from the previously mentioned exceptions (16-17,25,58-61), the majority of the evidence supports an inhibitory role of Que on DMEs and DTs.

Interplay between P-gp and CYP3A has been previously demonstrated $(38,62)$. P-gp increases the availability of a drug for metabolism by intestinal CYP3A by expelling it from enterocytes into the lumen of the intestine, thus promoting its metabolism (38). In addition, a previous study revealed that in CYP3A4-expressing Caco-2 cells, P-gp activity increased CsA metabolism (63). However, in the present study, the decrease in intestinal P-gp did not result in a marked increase in CsA plasma concentration. Therefore, other factors that remain to be identified, such as the interplay between other DMEs and DTs, may be involved in the metabolism of CsA.

As an extension to the idea of interplay between CYPs and efflux transporters, the dependence of phase II metabolic enzymes on efflux transporters was systematically illustrated utilizing various model systems, which may drive the metabolic disposition and clearance processes of flavonoids $(16,64)$. Notably, synergistic interplay between multiple phase II enzyme-efflux transporter combinations has been investigated, including UGTs-MRPs, UGTs-BCRP, SULTs-BCRP and GST-MRPs (64). Transport of metabolites increased the total metabolite formation (64), although the mechanistic basis of the synergistic interplay of DMEs and DTs remains to be elucidated. Therefore, the interplay between DMEs and DTs is hypothesized to explain the pharmacokinetic interactions between Que and CsA in the present study (38). 
As CsA is a dual substrate for DMEs and DTs, ex vivo investigations may not fully characterize the complex HDIs involved in the interplay between DMEs and DTs. As Que is an inhibitor of various DME and DT proteins, the results of the present study do not reveal whether the decrease in CsA concentration is the result of effects on DME/DT interplay, resulting in a decrease in the absorption of CsA, increased metabolism or a combination of the two. Therefore, the underlying mechanisms of the interaction revealed in the present study remain to be fully elucidated. In vitro studies may facilitate the identification of the underlying mechanisms involved in DME/DT interplay, and studies in human cells are required to determine any species-specific variations $(16,38)$.

Notably, Que primarily exists in plants as glycosides. Que glycosides are hydrolyzed and metabolized by DMEs in the intestines of animals and humans (65). Furthermore, it was recently demonstrated that Que 3-O- $\beta$-D-glucuronide and Que-3'-O-sulphate are the primary Que conjugates in human and animal plasma, in which Que glycosides or Que aglycone could not be detected $(66,67)$. In the present study, therefore, the Que metabolites rather than Que, may interact with DMEs and DTs in vivo. Various in vitro studies have revealed that the major phase II metabolites of Que were equal to or more potent than Que in the inhibition of MRP1, MRP2 and OAT1 $(60,68)$. Therefore, it is crucial to understand the metabolism of compounds in order to investigate their effects. Further investigation is required to determine the effects of Que metabolites on DMEs and DTs in vitro and in vivo.

In conclusion, for the first time, to the best of our knowledge, the present study demonstrated that, following multiple-dose co-administration to rats, Que reduced CsA bioavailability, seemingly in contrast to the individual inhibitory effect on mRNA and protein expression levels of DMEs and DTs in the small intestine and liver. Overlapping modulation of intestinal and hepatic DMEs and DTs, as well as their interplay, may be responsible for this observation. The results of the present study suggest a novel mechanism underlying flavonoid-drug interactions, and may be clinically significant for patients taking CsA and Que or Que-containing dietary/herbal supplements simultaneously.

\section{Acknowledgements}

The present study was supported by the National Natural Science Foundation of China (grant nos. 81273591 and 81503161) and the Fundamental Research Funds for the Central Universities (grant nos. 2014YGYL003 and 2016YXZD050).

\section{References}

1. Ma Y, Zeng M, Sun R and Hu M: Disposition of flavonoids impacts their efficacy and safety. Curr Drug Metab 15: 841-864, 2014.

2. Shi S and Klotz U: Drug interactions with herbal medicines. Clin Pharmacokinet 51: 77-104, 2012.

3. Morris ME and Zhang S: Flavonoid-drug interactions: Effects of flavonoids on ABC transporters. Life Sci 78: 2116-2130, 2006.

4. Egert S, Wolffram S, Bosy-Westphal A, Boesch-Saadatmandi C, Wagner AE, Frank J, Rimbach G and Mueller MJ: Daily quercetin supplementation dose-dependently increases plasma quercetin concentrations in healthy humans. J Nutr 138: 1615-1621, 2008.
5. Russo M, Spagnuolo C, Tedesco I, Bilotto S and Russo GL: The flavonoid quercetin in disease prevention and therapy: Facts and fancies. Biochem Pharmacol 83: 6-15, 2012.

6. Cai X, Fang Z, Dou J, Yu A and Zhai G: Bioavailability of quercetin: Problems and promises. Curr Med Chem 20: 2572-2582, 2013.

7. Dajas F: Life or death: Neuroprotective and anticancer effects of quercetin. J Ethnopharmacol 143: 383-396, 2012.

8. Zal F, Mostafavi-Pour Z and Vessal M: Comparison of the effects of vitamin $E$ and/or quercetin in attenuating chronic cyclosporine A-induced nephrotoxicity in male rats. Clin Exp Pharmacol Physiol 34: 720-724, 2007.

9. Mostafavi-Pour Z, Zal F, Monabati A and Vessal M: Protective effects of a combination of quercetin and vitamin $\mathrm{E}$ against cyclosporine A-induced oxidative stress and hepatotoxicity in rats. Hepatol Res 38: 385-392, 2008.

10. Dodda D, Chhajed R and Mishra J: Protective effect of quercetin against acetic acid induced inflammatory bowel disease (IBD) like symptoms in rats: Possible morphological and biochemical alterations. Pharmacol Rep 66: 169-173, 2014.

11. Dodda D, Chhajed R, Mishra J and Padhy M: Targeting oxidative stress attenuates trinitrobenzene sulphonic acid induced inflammatory bowel disease like symptoms in rats: Role of quercetin. Indian J Pharmacol 46: 286-291, 2014.

12. Abarikwu SO, Pant AB and Farombi EO: The protective effects of quercetin on the cytotoxicity of atrazine on rat Sertoli-germ cell co-culture. Int J Androl 35: 590-600, 2012.

13. Abarikwu SO, Pant AB and Farombi EO: Quercetin decreases steroidogenic enzyme activity, $\mathrm{NF}-\kappa \mathrm{B}$ expression, and oxidative stress in cultured Leydig cells exposed to atrazine. Mol Cell Biochem 373: 19-28, 2013.

14. Tang Y, Gao C, Xing M, Li Y, Zhu L, Wang D, Yang X, Liu L and Yao P: Quercetin prevents ethanol-induced dyslipidemia and mitochondrial oxidative damage. Food Chem Toxicol 50: 1194-1200, 2012

15. Qu L, Liang X, Gu B and Liu W: Quercetin alleviates high glucose-induced Schwann cell damage by autophagy. Neural Regen Res 9: 1195-1203, 2014.

16. Jiang $\mathrm{W}$ and $\mathrm{Hu} \mathrm{M}$ : Mutual interactions between flavonoids and enzymatic and transporter elements responsible for flavonoid disposition via phase II metabolic pathways. RSC Adv 2: 7948-7963, 2012.

17. Duan KM, Wang SY, Ouyang W, Mao YM and Yang LJ: Effect of quercetin on CYP3A activity in Chinese healthy participants. J Clin Pharmacol 52: 940-946, 2012.

18. Priyadarsini RV and Nagini S: Quercetin suppresses cytochrome P450 mediated ROS generation and NFKB activation to inhibit the development of 7,12-dimethylbenz[a] anthracene (DMBA) induced hamster buccal pouch carcinomas. Free Radic Res 46: 41-49, 2012.

19. Chen Y, Xiao P, Ou-Yang DS, Fan L, Guo D, Wang YN, Han Y, Tu JH, Zhou G, Huang YF and Zhou HH: Simultaneous action of the flavonoid quercetin on cytochrome P450 (CYP) 1A2, CYP2A6, N-acetyltransferase and xanthine oxidase activity in healthy volunteers. Clin Exp Pharmacol Physiol 36: 828-833, 2009.

20. Rastogi H and Jana S: Evaluation of inhibitory effects of caffeic acid and quercetin on human liver cytochrome p450 activities. Phytother Res 28: 1873-1878, 2014.

21. Brand W, Schutte ME, Williamson G, van Zanden JJ, Cnubben NH, Groten JP, van Bladeren PJ and Rietjens IM: Flavonoid-mediated inhibition of intestinal ABC transporters may affect the oral bioavailability of drugs, food-borne toxic compounds and bioactive ingredients. Biomed Pharmacother 60: 508-519, 2006.

22. Alvarez AI, Real R, Pérez M, Mendoza G, Prieto JG and Merino G: Modulation of the activity of ABC transporters (P-glycoprotein, MRP2, BCRP) by flavonoids and drug response. J Pharm Sci 99: 598-617, 2010.

23. van Zanden JJ, Wortelboer HM, Bijlsma S, Punt A, Usta M, Bladeren PJ, Rietjens IM and Cnubben NH: Quantitative structure activity relationship studies on the flavonoid mediated inhibition of multidrug resistance proteins 1 and 2. Biochem Pharmacol 69: 699-708, 2005.

24. Odenthal J, van Heumen BW, Roelofs HM, te Morsche RH, Marian B, Nagengast FM and Peters WH: The influence of curcumin, quercetin, and eicosapentaenoic acid on the expression of phase II detoxification enzymes in the intestinal cell lines HT-29, Caco-2, HuTu 80, and LT97. Nutr Cancer 64: 856-863, 2012. 
25. Wang SY, Duan KM, Li Y, Mei Y, Sheng H, Liu H, Mei X, Ouyang W, Zhou HH and Liu ZQ: Effect of quercetin on P-glycoprotein transport ability in Chinese healthy subjects. Eur J Clin Nutr 67: 390-394, 2013.

26. Wu LX, Guo CX, Chen WQ, Yu J, Qu Q, Chen Y, Tan ZR, Wang G, Fan L, Li Q, et al: Inhibition of the organic anion-transporting polypeptide $1 \mathrm{~B} 1$ by quercetin: $\mathrm{An}$ in vitro and in vivo assessment. Br J Clin Pharmacol 73: 750-757, 2012.

27. Tedesco D and Haragsim L: Cyclosporine: A review. J Transplant 2012: 230386, 2012

28. Dupuis R, Yuen A and Innocenti F: The influence of UGT polymorphisms as biomarkers in solid organ transplantation. Clin Chim Acta 413: 1318-1325, 2012.

29. Kato R, Nishide M, Kozu C, Iwamoto A, Urashima K, Suzuki K, Ijiri Y, Hayashi T and Tanaka K: Is cyclosporine A transport inhibited by pravastatin via multidrug resistant protein 2? Eur J Clin Pharmacol 66: 153-158, 2010.

30. Fu J, Tjandra M, Becker C, Bednarczyk D, Capparelli M, Elling R, Hanna I, Fujimoto R, Furegati M, Karur S, et al: Potent nonimmunosuppressive cyclophilin inhibitors with improved pharmaceutical properties and decreased transporter inhibition. J Med Chem 57: 8503-8516, 2014.

31. Li L, Yao QQ, Xu SY, Hu HH, Shen Q, Tian Y, Pan LY, Zhou H, Jiang HD, Lu C, et al: Cyclosporin A affects the bioavailability of ginkgolic acids via inhibition of P-gp and BCRP. Eur J Pharm Biopharm 88: 759-767, 2014.

32. Yu CP, Wu PP, Hou YC, Lin SP, Tsai SY, Chen CT and Chao PD: Quercetin and rutin reduced the bioavailability of cyclosporine from Neoral, animmunosuppressant, through activating P-glycoprotein and CYP 3A4. J Agric Food Chem 59: 4644-4648, 2011.

33. Choi JS, Choi BC and Choi KE: Effect of quercetin on the pharmacokinetics of oral cyclosporine. Am J Health Syst Pharm 61: 2406-2409, 2004

34. Yang CY, Chao PD, Hou YC, Tsai SY, Wen KC and Hsiu SL: Marked decrease of cyclosporin bioavailability caused by coadministration of ginkgo and onion in rats. Food Chem Toxicol 44 $1572-1578,2006$

35. Hsiu SL, Hou YC, Wang YH, Tsao CW, Su SF and Chao PD Quercetin significantly decreased cyclosporin oral bioavailability in pigs and rats. Life Sci 72: 227-235, 2002.

36. Hsu PW, Shia CS, Lin SP, Chao PD, Juang SH and Hou YC: Potential risk of mulberry-drug interaction: Modulation on P-glycoprotein and cytochrome P450 3A. J Agric Food Chem 61: 4464-4469, 2013.

37. Colombo D, Lunardon L and Bellia G: Cyclosporine and herbal supplement interactions. J Toxicol 2014: 145325, 2014

38. Shi S and Li Y: Interplay of Drug-Metabolizing enzymes and transporters in drug absorption and disposition. Curr Drug Metab 15: 915-941, 2014

39. Wu B: Pharmacokinetic interplay of phase II metabolism and transport: A theoretical study. J Pharm Sci 101: 381-393, 2012.

40. Lei H, Luo J, Tong L, Peng LQ, Qi Y, Jia ZG and Wei Q: Quercetin binds to calcineurin at a similar region to cyclosporin A and tacrolimus. Food Chem 127: 1169-1174, 2011

41. Barbas CF III, Burton DR, Scott JK and Silverman GJ: Quantitation of DNA and RNA. CSH Protoc 2007:pdb.ip47, 2007.

42. Livak KJ and Schmittgen TD: Analysis of relative gene expression data using real-time quantitative PCR and the 2(-Delta Delta C(T)) Method. Methods 25: 402-428, 2001.

43. Kim KA, Park PW and Park JY: Short-term effect of quercetin on the pharmacokinetics of fexofenadine, a substrate of P-glycoprotein, in healthy volunteers. Eur J Clin Pharmacol 65 : 609-614, 2009

44. Kim KA, Park PW, Kim HK, Ha JM and Park JY: Effect of quercetin on the pharmacokinetics of rosiglitazone, a CYP2C8 substrate, in healthy subjects. J Clin Pharmacol 45: 941-946, 2005 .

45. Choi JS, Jo BW and Kim YC: Enhanced paclitaxel bioavailability after oral administration of paclitaxel or prodrug to rats pretreated with quercetin. Eur J Pharm Biopharm 57: 313-318, 2004

46. Challa VR, Babu PR, Challa SR, Johnson B and Maheswari C: Pharmacokinetic interaction study between quercetin and valsartan in rats and in vitro models. Drug Dev Ind Pharm 39 865-872, 2013

47. Babu PR, Babu KN, Peter PL, Rajesh K and Babu PJ: Influence of quercetin on the pharmacokinetics of ranolazine in rats and in vitro models. Drug Dev Ind Pharm 39: 873-879, 2013.
48. Shin SC, Choi JS and Li X: Enhanced bioavailability of tamoxifen after oral administration of tamoxifen with quercetin in rats. Int $\mathrm{J}$ Pharm 313: 144-149, 2006.

49. Choi JS, Piao YJ and Kang KW: Effects of quercetin on the bioavailability of doxorubicin in rats: Role of CYP3A4 and P-gp inhibition by quercetin. Arch Pharm Res 34: 607-613, 2011.

50. Wang YH, Chao PD, Hsiu SL, Wen KC and Hou YC: Lethal quercetin-digoxin interaction in pigs. Life Sci 74: 1191-1197, 2004.

51. Nguyen MA, Staubach P, Wolffram S and Langguth P: Effect of single-dose and short-term administration of quercetin on the pharmacokinetics of talinolol in humans-Implications for the evaluation of transporter-mediated flavonoid-drug interactions. Eur J Pharm Sci 61: 54-60, 2014.

52. Challa SR, Challa VR and Ragam SK: Quercetin declines plasma exposure of metoprolol tartrate in the rat model. J Adv Pharm Technol Res 5: 185-190, 2014

53. Cermak R, Wein S, Wolffram S and Langguth P: Effects of the flavonol quercetin on the bioavailability of simvastatin in pigs. Eur J Pharm Sci 38: 519-524, 2009.

54. Burke JF Jr, Pirsch JD, Ramos EL, Salomon DR, Stablein DM, Van Buren DH and West JC: Long-term efficacy and safety of cyclosporine in renal-transplant recipients. N Engl J Med 331: 358-363, 1994.

55. Kronbach T, Fischer V and Meyer UA: Cyclosporine metabolism in human liver: Identification of a cytochrome P-450III gene family as the major cyclosporine-metabolizing enzyme explains interactions of cyclosporine with other drugs. Clin Pharmacol Ther 43: 630-635, 1988

56. Elens L, Bouamar R, Shuker N, Hesselink DA, van Gelder T and van Schaik RH: Clinical implementation of pharmacogenetics in kidney transplantation: Calcineurin inhibitors in the starting blocks. Br J Clin Pharmacol 77: 715-728, 2014

57. Yu ES, Min HJ, An SY, Won HY, Hong JH and Hwang ES: Regulatory mechanisms of IL-2 and IFNgamma suppression by quercetin in T helper cells. Biochem Pharmacol 76: 70-78, 2008.

58. van der Logt EM, Roelofs HM, Nagengast FM and Peters WH: Induction of rat hepatic and intestinal UDP-glucuronosyltransferases by naturally occurring dietary anticarcinogens. Carcinogenesis 24: 1651-1656, 2003.

59. Mitsunaga $Y$, Takanaga $H$, Matsuo $H$, Naito M, Tsuruo T, Ohtani $\mathrm{H}$ and Sawada $\mathrm{Y}$ : Effect of bioflavonoids on vincristine transport across blood-brain barrier. Eur J Pharmacol 395 193-201, 2000

60. van Zanden JJ, van der Woude H, Vaessen J, Usta M, Wortelboer HM, Cnubben NH and Rietjens IM: The effect of quercetin phase II metabolism on its MRP1 and MRP2 inhibiting potential. Biochem Pharmacol 74: 345-351, 2007.

61. Ebert B, Seidel A and Lampen A: Phytochemicals induce breast cancer resistance protein in Caco-2 cells and enhance the transport of benzo[a]pyrene-3-sulfate. Toxicol Sci 96: 227-236, 2007.

62. Benet LZ: The drug transporter-metabolism alliance: Uncovering and defining the interplay. Mol Pharm 6: 1631-1643, 2009.

63. Gan LS, Moseley MA, Khosla B, Augustijns PF, Bradshaw TP, Hendren RW and Thakker DR: CYP3A-like cytochrome P450-mediated metabolism and polarized efflux of cyclosporin A in Caco-2 cells. Drug Metab Dispos 24: 344-349, 1996.

64. Li Y, Zhou J, Ramsden D, Taub ME, O'Brien D, Xu J, Busacca CA, Gonnella N and Tweedie DJ: Enzyme-transporter interplay in the formation and clearance of abundant metabolites of faldaprevir found inexcreta but not in circulation. Drug Metab Dispos 42: 384-393, 2014

65. Chen X, Yin OQ, Zuo Z and Chow MS: Pharmacokinetics and modeling of quercetin and metabolites. Pharm Res 22: 892-901, 2005.

66. Ishizawa K, Yoshizumi M, Kawai Y, Terao J, Kihira Y, Ikeda Y, Tomita S, Minakuchi K, Tsuchiya K and Tamaki T: Pharmacology in health food: Metabolism of quercetin in vivo and its protective effect against arteriosclerosis. J Pharmacol Sci 115: 466-470, 2011.

67. Yokoyama A, Sakakibara H, Crozier A, Kawai Y, Matsui A, Terao J, Kumazawa S and Shimoi K: Quercetin metabolites and protection against peroxynitrite-induced oxidative hepatic injury in rats. Free Radic Res 43: 913-921, 2009.

68. Wong CC, Botting NP, Orfila C, Al-Maharik $\mathrm{N}$ and Williamson G: Flavonoid conjugates interact with organic anion transporters (OATs) and attenuate cytotoxicity of adefovir mediated by organic anion transporter 1 (OAT1/SLC22A6). Biochem Pharmacol 81: 942-949, 2011. 